BULLETIN Bulletin hispanique

HISPANIQUE Université Michel de Montaigne Bordeaux

$119-2 \mid 2017$

La Égloga renacentista en el Reino de Nápoles

\title{
Galatea, o la idea de la belleza garcilasiana
}

\section{Roland Béhar}

\section{(2) OpenEdition}

\section{Journals}

Edición electrónica

URL: http://journals.openedition.org/bulletinhispanique/5133

DOI: 10.4000/bulletinhispanique.5133

ISSN: 1775-3821

\section{Editor}

Presses universitaires de Bordeaux

\section{Edición impresa}

Fecha de publicación: 1 diciembre 2017

Paginación: 591-620

ISBN: 979-10-300-0218-8

ISSN: 0007-4640

\section{Referencia electrónica}

Roland Béhar, «Galatea, o la idea de la belleza garcilasiana», Bulletin hispanique [En línea], 119-2 | 2017, Publicado el 28 diciembre 2020, consultado el 13 enero 2021. URL: http://journals.openedition.org/ bulletinhispanique/5133 ; DOI: https://doi.org/10.4000/bulletinhispanique.5133 


\title{
Galatea, o la idea de la belleza garcilasiana ${ }^{1}$
}

\author{
ROLAND BÉHAR \\ École Normale Supérieure, París
}

L'analyse des implications poétiques du choix du nom de «Galatea» dans l'Églogue I de Garcilaso, permet de montrer comment la création du poète tolédan doit se comprendre depuis la poésie napolitaine de son temps et depuis les multiples réécritures du mythe de Galathée de Théocrite et de Virgile dont il put y prendre connaissance. Labsence d'informations sur les circonstances de la création de l'Églogue I ne doit pas en cacher l'évidente fonction courtisane.

Mots-clés: Garcilaso de la Vega, églogue, Galathée, pétrarquisme napolitain, Virgile, Théocrite, cour.

A partir del análisis de las implicaciones poéticas de la elección del nombre de Galatea en la Égloga I de Garcilaso, se pretende mostrar cómo la creación garcilasiana debe entenderse desde la poesía napolitana de su tiempo y desde las múltiples reescrituras del mito teocríteo y virgiliano de Galatea, que el toledano pudo conocer allí. Se subraya que la ausencia de datos sobre las circunstancias de la creación de la Égloga I no debe ocultar su evidente función cortesana.

Palabras clave: Garcilaso de la Vega, égloga, Galatea, petrarquismo napolitano, Virgilio, Teócrito, corte.

Through the analysis of the poetic implications of the choice of the name "Galatea" in Garcilaso's 'Eclogue I', this article aims to show how the works of the Toledo poet must be understood, from the perspective of the Neapolitan poetry of his time and, in this case, from the many rewritings of the Theocritian and Virgilian myth of Galatea, which he could have discovered there. The absence of information on the circumstances surrounding the creation of 'Eclogue I' should not hide its obvious courtier function.

Keywords: Garcilaso de la Vega, eclogue, Galatea, Neapolitan Petrarchism, Virgil, Theocritus, court.

1. Quien escribe estas líneas desea expresar su más sincera gratitud hacia Tobia R. Toscano, Jesús Ponce Cárdenas, Maria D’Agostino, Flavia Gherardi y Gáldrick de la Torre Ávalos, por su atenta lectura y sus valiosas sugerencias. 


\author{
¡Oh más dura que mármol a mis quejas, \\ $y$ al encendido fuego en que me quemo \\ más helada que nieve, Galatea! [... $]^{2}$
}

$\mathrm{E}$ stos versos de Garcilaso cuentan, no cabe duda de ello, entre los más celebrados y recordados por la posteridad de la obra del toledano. Los contrastes iniciales, entre el dolorido sentir de las quejas y la dureza del mármol ${ }^{3}$, entre el fuego y la nieve, introducen uno de los pasajes más comentados: la querella amorosa que el pastor Salicio, en la égloga I, dirige a la bella Galatea, que lo ha abandonado por otro, con clarísimas reminiscencias de Teócrito, Virgilio y Ovidio. Desde el siglo XVI, cuando Fernando de Herrera afirmara de ella que «es aventajada de las otras en todas las partes, que requiere este género [bucólico]» ${ }^{4}$, esta égloga de Garcilaso ha dado lugar a numerosos intentos de interpretación. Entre ellos, merece la pena destacar aquellos que insisten, subrayando su dimensión intertextual, en los ecos del texto con las Bucólicas de Virgilio, pero también, para la segunda parte -en la que Salicio le cede el puesto a Nemoroso-, con la Arcadia de Sannazaro, con lo cual se llega al esquema de una perfecta imitatio que recrea en lengua castellana el mundo pastoral clásico e italiano 5 .

Por la multiplicidad de ecos que suscita en cuanto se pronuncia, la elección del nombre de Galatea, en la primera mitad de la égloga, supone la reivindicación, por parte de Garcilaso, de toda una herencia literaria en la estela de la cual concibe su quehacer literario. La designación onomástica permite entrar en un complejo conjunto de consideraciones a la vez sobre el texto y sobre el contexto cortesano que implica ${ }^{6}$. En efecto, la larga dedicatoria al virrey de las

2. Garcilaso de la Vega, Obra poética, ed. Bienvenido Morros, estudio preliminar de Rafael Lapesa, Barcelona, Crítica, 1995, p. 123.

3. Oposición reactivada más adelante en las quejas de Salicio (vv. 197-198): «Con mi llorar las piedras enternecen / su natural dureza y la quebrantan».

4. Fernando de Herrera, Anotaciones a la poesía de Garcilaso, ed. Inoria Pepe y José María Reyes, Madrid, Cátedra, 2001, p. 694.

5. Sobre la égloga I, véanse los estudios siguientes: M. J. Woods, «Rhetoric in Garcilaso’s First Eclogue», Modern Language Notes, vol. 84, 1969, pp. 143-156; Sydney P. Cravens y Edward V. George, «Garcilaso's Salicio and Vergil's Eighth Eclogue», Hispania, vol. 64, 1981, pp. 209214; Luis Iglesias Feijoo, «Lectura de la Égloga I», en Academia Literaria Renacentista. IV: Garcilaso, Salamanca, Universidad de Salamanca, 1983, pp. 61-82; Cesare Segre, «Análisis conceptual de la Égloga I de Garcilaso", en id., El buen amor del texto. Estudios españoles, Barcelona, Destino, 2004, pp. 73-99; Pedro Córdoba, «Sous le signe de Diane: étude ethnologique des Églogues de Garcilaso", en Hommage à Augustin Redondo, Paris, Publications de la Sorbonne-Presses de la Sorbonne Nouvelle, 2001, pp. 473-498; y, ahora, las páginas dedicadas a la égloga por Flavia Gherardi en este mismo volumen del Bulletin Hispanique.

6. Sobre la significación de los nombres, véase Roland Béhar, «L'onomastique bucolique dans la poésie de Garcilaso de la Vega: le modèle de Virgile et des poètes de l'Académie pontanienne», 
tres primeras estrofas se despliega con un movimiento circular que va desde «El dulce lamentar de dos pastores...» (v. 1) hasta la propositio final «...escucha tú el cantar de mis pastores» (v. 42), que supone la presencia real del virrey. Pese a ello, la crítica que ha examinado la égloga I pocas veces ha reparado en las condiciones históricas de su producción. Y, cuando lo ha hecho, ha sido para determinar con mayor exactitud el momento de su composición y, en regla general, para poder relacionar el texto con la vida sentimental del vate. No se suele considerar, en cambio, que la escritura de esta égloga haya podido ser motivada por las circunstancias cortesanas, que son las que determinan la existencia de Garcilaso a partir de 1532. No es este el lugar para evocar el entramado cortesano de la estancia del poeta en la capital partenopea ${ }^{9}$, pero sí será útil recordar las implicaciones teóricas que la poesía cortesana había ido concentrando en torno al nombre de Galatea desde finales del siglo XV.

En lo que sigue, usando datos en parte ya bien conocidos, se considerará la importancia del mismo nombre de Galatea y se recordará su recuperación entre Florencia y Roma, con la herencia clásica, en los últimos años del Quattrocento, que convierte a Galatea en un verdadero icono del Renacimiento a la par que símbolo de la doblez del sentimiento amoroso. De particular importancia

en Itinera Parthenopea. L'exemplum virgilien et l'Académie napolitaine à la Renaissance, Paris, Classiques Garnier, 2017, t. I, en prensa, e id., «The Poetry of Garcilaso: Bucolic Tradition and the Invention of a Visual Signature», Bulletin of Spanish Studies, vol. 94, no 3, 2017, pp. 1-13, donde se evocan en especial las múltiples resonancias del nombre de Salicio, posible anagrama de Garcilaso, pero también eco de la égloga Salices de Sannazaro.

7. Véase Roland Béhar, “Tu mihi”: variaciones bucólicas sobre un ritual de dedicatoria, de Virgilio a Góngora", Nueva revista de filología hispánica, vol. 61, n 1, 2013, pp. 65-98.

8. Véase sobre el asunto Herman Iventosch, Los nombres bucólicos en Sannazaro y la pastoral española: ensayo sobre el sentido de la bucólica en el Renacimiento, Valencia, s. n., 1975, pp. 109113. Para algunos intentos de identificación, además de lo apuntado por El Brocense (1574) y Herrera (1580, para lo cual cf. F. de Herrera, Anotaciones..., op. cit., p. 695), véanse Adrien Roig, «¿Quiénes fueron Salicio y Nemoroso?», Criticón, no 4, 1978, pp. 1-36; Luís de Sá Fardilha, «Beatriz de Sá: a improvável Elisa de Garcilaso de la Vega», Península: revista de estudios ibéricos, $\mathrm{n}^{\circ}$ 1, 2004, pp. 97-105; Bienvenido Morros, «Albanio como don Fernando de Toledo en la égloga II de Garcilaso», Analecta Malacitana, vol. 31, no 1, 2008, pp. 7-29; e id., «La muerte de Isabel Freyre y el amor napolitano de Garcilaso. Para una cronología de sus églogas y de otros poemas», Criticón, no 150, 2009, pp. 5-35.

9. Véase el artículo histórico de Eugenio Mele, «Las poesías latinas de Garcilaso de la Vega y su permanencia en Italia», Bulletin Hispanique, vol. 25, no 2, 1923, pp. 108-148, así como Carlos José Hernando Sánchez, Castilla y Nápoles en el siglo XVI: el virrey Pedro de Toledo: linaje, estado y cultura (1532-1553), Valladolid, Junta de Castilla y León, 1994 y, sobre todo, id., "Parthénope, ¿tan lejos de su tierra? Garcilaso de la Vega y la poesía de la corte en Nápoles», en José María Díez Borque y Luis Ribot García (eds.), Garcilaso y su época: del amor y la guerra, Madrid, Sociedad Estatal de Conmemoraciones culturales, 2003, pp. 71-141. En términos generales, sobre la filiación de las églogas garcilasianas respecto a la tradición bucólica, véanse -esenciales para los problemas aquí estudiados- Darío Fernández-Morera, The Lyre and the Oaten Flute: Garcilaso and the Pastoral, London, Tamesis Books, 1982, y Antonio Gargano, «L'Egloga a Napoli tra Sannazaro e Garcilaso», en id., Con Accordato Canto. Studi sulla poesia tra Italia e Spagna nei secoli XV-XVII, Napoli, Liguori Editore, 2005, pp. 181-201, así como su artículo en este volumen del Bulletin hispanique. 
resulta en este contexto la égloga piscatoria Galatea de Sannazaro, así como la proliferación de composiciones neolatinas y en volgare que toman a Galatea por tema en los años en que Garcilaso concibe su égloga. Según se verá, este fenómeno se ha de entender no solo como señal de la fortuna del género bucólico desde finales del siglo XV, sino también como efecto de la utilización de la figura de Galatea para el discurso cortesano sobre el amor. Se procurará mostrar, con esto, el papel esencial de las reescrituras del mito de Galatea a partir de 1500, así como la creciente dimensión cortesana del mismo, que necesariamente tuvieron que influir en Garcilaso en el momento de elegir el nombre de la amada de Salicio y de concebir la égloga I.

\section{El nombre de Galatea}

Un punto relativamente desatendido por la crítica, probablemente en razón de su misma obviedad, es el de la elección del nombre de la esquiva pastora amada por Salicio, Galatea. Fernando de Herrera, en sus Anotaciones (1580), daba una interpretación escueta, aunque conforme con la tradición clásica: «Una de las Ninfas Nereidas, llamada así por su blancura del esplendor y claridad de las espumas del mar; porque $\gamma \alpha \dot{\lambda} \lambda \alpha$ es leche en el lenguaje griego» ${ }^{10}$. De hecho, desde Teócrito y, sobre todo, desde Virgilio, el nombre se asociaba con la imagen de una ninfa inaccesible, sorda ante los ruegos de los pastores desesperados. Estos pastores eran, en regla general, el mismo cíclope Polifemo, o algún pastor desdeñado equiparable con él. Desde sus inicios, esta figura de Galatea apareció como la encarnación del amor desdichado, causa de sufrimiento, tal como la poesía medieval la repetiría con la imagen de la belle dame sans mercy ${ }^{11}$.

Las palabras inaugurales del undécimo idilio de Teócrito definen la intención del poema, a la vez cura y burla del amor infeliz (vv. 1-6):

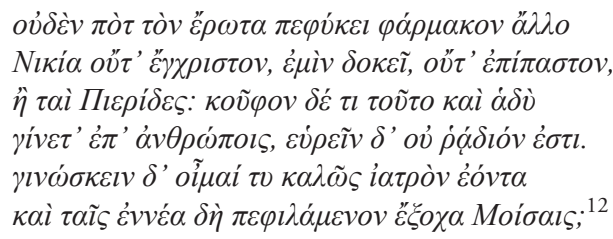

10. F. de Herrera, Anotaciones..., op. cit., p. 703.

11. Para un recorrido general, véase Heinrich Dörrie, Die Schöne Galatea: eine Gestalt am Rande des Griechen Mythos in Antiker und Neuzeitlicher Sicht, München, Ernst Heimeran Verlag, 1968, así como el artículo, muy instructivo para el asunto aquí estudiado, de Michael Paschalis, «Tityrus and Galatea (Virgil, Eclogue 1): An Expected Relationship», Dictynna. Revue de poétique latine, no 5, 2008, https://dictynna.revues.org/401. Fundamental, por fin, la síntesis de Beate Czapla, «Die Wandlung der Nereide Galatea von einer Kokotte zur Heligen oder die Usurpation eines griechischen Mythos durch den Petrarkismus», Antike und Abendland, vol. 52, 2006, pp. 95-125. También, las páginas que dedica al asunto Jesús Ponce Cárdenas en su edición de Luis de Góngora, Fábula de Polifemo y Galatea, Madrid, Cátedra, 2010, pp. 33-45.

12. Bucoliques grecs. Théocrite, ed. y trad. Ph.-E. Legrand, Paris, Les Belles Lettres, 1946, t. I, p. 74 (traducción de quien escribe). 
No hay remedio contra el amor,

Nicias, ni ungüento, me parece, ni polvo,

si no es el comercio de las Piérides: es un alivio grato

para los hombres, pero difícil de hallar.

Bien lo sabes, me parece, tú que, siendo médico,

gozas del favor especial de las nueve Musas.

Teócrito hace del canto del cíclope a la vez el síntoma de su dolencia

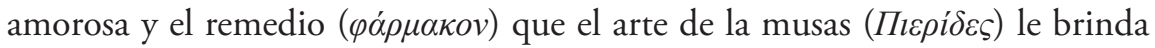
al pastor para librarse de su sufrimiento ${ }^{13}$. Dentro del marco abierto con este preámbulo, se alza luego el canto del mítico jayán, dedicado a la celebración de la belleza de Galatea, causa de su pena y a la que el cíclope dirige su canto

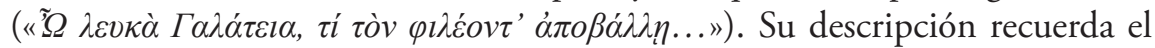
canon de la belleza de la poesía alejandrina. La bella aparece con la blancura

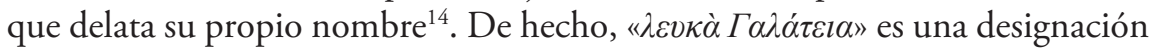
redundante, en cuanto es la "blanca láctea», "más blanca que la cuajada» (

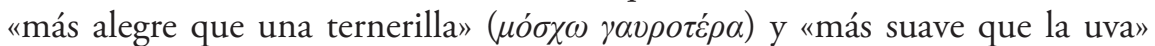
( de Galatea más adelante, con ocasión de las blancas nieves del Etna o de los blancos lirios que Polifemo le quiere obsequiar a la bella nereida a modo de homenaje a su blancura ${ }^{15}$.

Sin embargo, entrelazado con este motivo de la blancura, aparece desde el primer verso el carácter esquivo de la nereida: «¿por qué rechazas a quien te ama?»

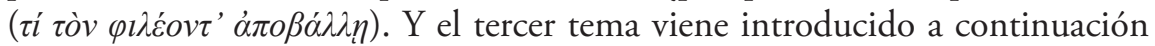
de la serie de comparaciones destinadas a ensalzar la hermosura de Galatea: la bella aparece en el sueño de Polifemo y se retira cuando se despierta ${ }^{16}$. El símil final de la oveja que huye ante el blanco lobo viene introducido por el verbo $\varphi \varepsilon \dot{\gamma} \gamma \iota \varsigma$, esencial para la caracterización de la ninfa, esquiva y, además, huidiza,

13. En la traducción del alemán Eobanus Hessus, publicada en 1531, la yuxtaposición de los términos insiste en la noción del «remedio de las Musas» (pharmaca Musae) y se detiene más en el dulce efecto de este sobre las llagas del enamorado (Theocriti Syracusani Idyllia Triginta sex, Latino Carmine reddita, Helio Eobano Hesso Interprete, Haguenau, Johann Setzer, 1531, fol. D6r $\left.{ }^{\circ}\right)$ : «Arte pharetrato factum grave vulnus amori / Si medica curare voles, seu pulvere sicco / Nicia conspergis, seu pulvere collinis udo / Haud quaquam prodesse queas, nisi pharmaca Musae / Quae laesis adhibere solent apponere cures I Iucunda illa quidem mortalibus esse videntur / Vulnereque affectis attactu lenia molli / Qua tamen inveniant multi ratione laborant / Et paucis ea nosce datur, sed enim tua Musae / Pectora cum foveant studii coelestis amore / Et Phoebi medicas tractes foeliciter artes / Haud ignota tibi Musarum ea dona putarim».

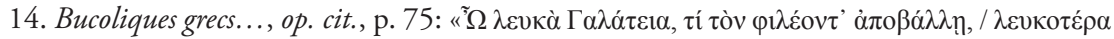

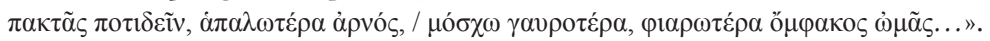

15. Para un comentario detenido, véanse Helen H. Law, «The Name Galatea in the Pygmalion Myth», The Classical Journal, vol. 22, n 5, 1932, pp. 337-342, e Ignasi Ribó Labastida, «Galatea o la leche. La descripción de la belleza femenina en Teócrito, Ovidio y Góngora», Parnaseo, no 10, 2006, http://parnaseo.uv.es/Lemir/Revista/Revista10/Ribo/IgnasiRibo.htm.

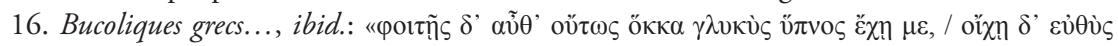

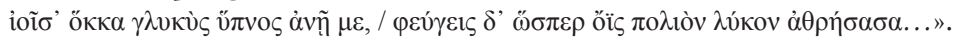


con lo cual se va identificando con el carácter más general de la ninfa ${ }^{17}$. Es de subrayar, por fin, que el poema de Teócrito es de carácter jocoso y tiene como objetivo la diversión del lector tanto como su adoctrinamiento: la misma ridiculez de Polifemo enamorado incita a huir el tipo de pasión amorosa que padece. Existen representaciones pictóricas antiguas que coinciden con este propósito, como un fresco que se conserva, hoy apenas reconocible, en el tablinum de la Casa de Livia, en Roma: a la izquierda, Galatea cabalga un caballo encima del agua; a la derecha, se ve a Polifemo entre los escollos, con el agua hasta el pecho, y a Cupido sobre sus hombros sujetándolo con las riendas del amor.

En esta presentación del mito de Polifemo y Galatea resulta totalmente ausente Acis, el bello joven que Galatea ama y que muere a manos de un Polifemo celoso. Probablemente este motivo narrativo se deba a la inventiva del mismo Ovidio, como eco del relato homérico de Ulises ${ }^{18}$. Este ańadido cambia en realidad por completo el relato, que conocería un increíble desarrollo con las reescrituras de Chiabrera, Góngora y tantos otros, hasta el siglo XVIII. Constituye, por tanto, un añadido respecto a la línea original que se conserva en su versión plasmada por Teócrito y que sigue siendo fundamental, aunque ya algo desdibujada, en el texto bucólico de Virgilio.

El poeta latino recordaría a Galatea en cuatro de sus Bucólicas: en I, 30-31 y en III, 64, 72, donde aparece como pastora, y en VII, 35 sqq. y IX, $37-$ 43 , donde es la nereida heredada del poeta siciliano. La primera de estas dos últimas ocurrencias es especialmente interesante, ya que convoca la imagen de la ninfa huidiza como objeto no del deseo de Polifemo, sino del cantante que se identifica con el cíclope: «Huc ades, o Galatea; quis est nam ludus in undis?» (IX, 39). Se debe a Virgilio, pues, el haber desligado el nombre de la nereida, convirtiéndolo en el nombre por antonomasia de la bella inalcanzable. Según se ha visto, Ovidio le daría una orientación nueva al mito en sus Metamorfosis (XIII, 789-865), al introducir la figura del competidor, Acis, a quien Polifemo acaba aplastando bajo la roca que sus celos le hacen lanzar. El Ovidius moralizatus de Pierre Bersuire proporciona una clave destacada, merced a la interpretación alegórica de la nereida en tanto alba dea, bipartición que ocasionaría la adaptación ortográfica Gala-thea, frecuente durante el Renacimiento. La figuración del esquivo numen como «diosa blanca», también inducida por la homonimia con la Galatea de Pigmalión (Ovidio, Metamorfosis, X, 243-297), cohonestaría durante la Edad Media una suerte de purificación progresiva de Galatea, en tanto modelo de virtud.

Así es cómo, en especial, en la undécima égloga de su Bucolicum carmen, Galathea, Petrarca identificó a la ninfa con la Laura que había cantado tanto

17. Véase Roland Béhar, «La eternizada fuga de la ninfa: De Garcilaso a Warburg», Calíope: Journal of the Society for Renaissance and Baroque Hispanic Poetry, vol. 20, no 2, 2015, pp. 19-38.

18. Véase Sara Mack, "Acis and Galatea or Metamorphosis of Tradition», Arion: A Journal of Humanities and the Classics, vol. 6, no 3, 1999, pp. 51-67. Además, cf. H. Dörrie, Die schöne Galatea..., op. cit., pp. 55 sq.; Alan H. F. Griffin, «Unrequited Love: Polyphemus and Galatea in Ovid's Metamorphoses», Greece \& Rome, no 30, 1983, pp. 190-197, aquí p. 192. 
en su versos en volgare. Fulgida llora la reciente muerte de Laura ${ }^{19}$. El pasaje celebra el recuerdo de Galatea, muerta en un lugar dedicado a su memoria ( liquit...»). La belleza de Galatea es su rasgo primordial, con el entrelazamiento de su nombre y de su epíteto con la mención de su cuerpo («Galatea suum pulcherrima corpus»). La muerte afectó a todas las partes de esta belleza: los miembros rosados (roseos artus), el blanco cuello (candida colla), las mejillas (genas), los ojos como astros (sydereos oculos) y el sereno rostro (vultus serenos). ¿De qué sirven tantas virtudes, si Galatea huyó desnuda de la amada cárcel de su cuerpo? No huyó desnuda, responde Niobe, sino revestida de la gloria inmarcesible de su nombre -eternizada por el poeta- ${ }^{20}$. Petrarca constituyó así a Laura-Galatea en modelo para todas las mujeres que desearían brillar en el futuro, por la belleza del cuerpo como por la del alma, por el canto como por las palabras. Todas tendrían que tenerla presente ante los ojos («deferet ante oculos»), lo cual convirtió a la hermosa ninfa en el modelo acabado no solo de la perfección femenina, sino también en el lugar donde la poesía tiene que actualizar el ideal artístico de la descripción. El «ejemplo del pudor» (exemplar pudicitiae), la «belleza de aspecto» (forma decoris) de Galatea siempre permanecerán en el corazón del poeta -hasta cuando baje al Leteo: incluso entonces, el pecho del poeta estará habitado por el nombre de Galatea y publicará su gloria-.

Tal como lo mostrara Alejandro Coroleu, el Bucolicon Carmen de Petrarca gozó de una notable difusión europea hasta mediados del siglo $\mathrm{XVI}^{21}$. Los poetas herederos de Petrarca tendrían presente aquella declaración de intenciones del poeta de Laura, quien sería también el poeta de Galatea. No resulta descabellado, pues, aproximar aquellos versos de Petrarca a estos de la égloga III de Garcilaso, en los que, cual nuevo Orfeo, promete publicar la gloria del nombre de su dedicataria (vv. 9-16):

Y aun no se me figura que me toca aqueste oficio solamente en vida,

19. Véase Francesco Petrarca, Opere, ed. Emilio Bigi, Milano, Mursia, 1979, pp. 388-390 (vv. 78-88): «Fulgida. Hic liquit Galatea suum pulcherrima corpus; / Libera iamque polos et regia tecta Tonantis, I Ipsa quidem Superumque choros mensasque frequentat. / Mors roseos artus, mors candida colla genasque / Sydereosque oculos tetigit, vultusque serenos / Obscura dimersit homo. Mortalia quisquam / Diligat, aut speret stabiles hic figere plantas? / Quid genus aut probitas? quid opes? quid forma? quid aetas? / Quidve decens cultus? Quid gloria nominis ingens? / Omnia contigerant; manus abstulit omnia mortis; / Nuda domum repetens e carcere fugit amato».

20. Ibid., pp. 390 (vv. 89-102): «Niobe. Nuda quidem minime, quam gloria vestii amictus I Clarior assidue longisque recentior annis. / Hanc quaecumque sibi vultuque animoque per aevum / Aut cantu aut sermone placens, cupiensque placere, / Deferet ante oculos. Hanc nos, dum spiritus iste / Artibus haerebit miseris et vivere coget, / Hanc, vel apud manes nebulosaque flumina Lethes, I Exemplarque pudicitiae, formamque decoris / Corde sub hoc semper memori pietate feremus. I Tum nostro, Galatea, tuum de pectore nomen / Exibit, fugient propriis dum sedibus astra; / Mellis apes studium linquent; nidosque columbae; / Coniugium turtur; praedam lupus; arbuta caprae; I Custodita dolos mulier; mendacia servus».

21. Alejandro Coroleu, Printing and Reading Italian Latin Humanism in Renaissance Europe (ca. 1470-ca. 1540), Cambridge, Cambridge Scholars Publishing, 2014, pp. 37-47. 


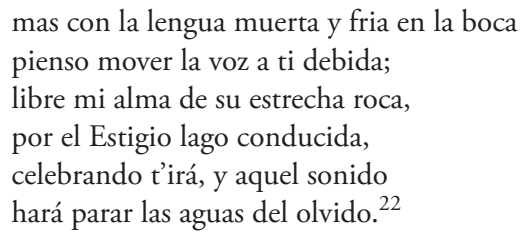

Aparecen aquí unidos los motivos de la celebración por Petrarca del nombre de la amada adaptados al proyecto de Garcilaso. No se trata, necesariamente, de un recuerdo literal, pero tampoco hace falta que así sea, ya que Petrarca, con todo su Canzoniere, desplegó exactamente este proyecto de inmortalización poética mediante la expansión textual del nombre de la amada, cuyo eco resuena sin cesar en sus versos (Laura, l'aura, lauro, l'auro...).

$\mathrm{Al}$ mismo tiempo que, con Petrarca, se produce la idealización de Galatea en un parangón de belleza en la poesía latina -lo que Laura es en volgare-, se observa, sin embargo, también cómo la difusión medieval de las Galateas desdibujó paulatinamente su imagen originaria, cada vez menos asociada con la blancura etimológica que le otorga su condición de ninfa con nombre «lácteo». Sería necesaria la vuelta al texto originario de Teócrito para devolver su fuerza expresiva al nombre de la ninfa, al mismo tiempo que este renacer del poeta siciliano causaría el retorno a una forma más genuina de la bucólica, menos alegórica y más apegada a sus modelos antiguos: Virgilio y, sobre todo, Teócrito.

Dos testimonios dan fe de ello, emanados de dos de los ingenios más preclaros de su generación: el llamado Triunfo de Galatea de Rafael Sanzio, para la Villa Farnesina en Roma, y la égloga piscatoria Galatea de Iacopo Sannazaro, en Nápoles. Ambas obras coincidieron en la creación de una imagen inédita de la belleza femenina, luego abundantemente imitada.

\section{GALATEA, ICONO DEL NEOCLASICISMO RENACENTISTA}

Garcilaso escribió en un ámbito sumamente embebido de modelos antiguos, Teócrito, Virgilio, Ovidio y muchos más, que nutren el constante trabajo de la imitatio $^{23}$. Comparte este rasgo con todos aquellos que, en Nápoles y más allá, vuelven a fundar una nueva estética, entre inspiración neolatina y vernácula, que se aparta del solo modelo bembiano y se orienta hacia la creación de una estética clásica o neo-clásica. Esta voluntad de clasicismo no significa en absoluto una voluntad de estilo hueca y falta de estilo. Todo lo contrario: expresa la sensación, o conciencia, de vivir en una época que se percibe bajo ciertos aspectos como la de una plenitudo temporis. Esta conciencia, fuertemente

22. G. de la Vega, Obra poética..., op. cit., p. 230.

23. Para una estudio reciente sobre la cuestión desde la ladera hispánica, véase Jesús Ponce Cárdenas, La imitación áurea. Cervantes, Quevedo, Góngora, Paris, Les Éditions Hispaniques, 2016 . 
desarrollada por los humanistas de la corte papal de León X (1513-1521) y por todos aquellos en contacto con ellos, serviría después de matriz, como se ha mostrado en otro lugar y como la historia del arte sabe desde hace tiempo, para la renovación estética e ideológica del imperio de Carlos $\mathrm{V}^{24}$. Son múltiples los aspectos de este renacer del clasicismo, buscado con plena voluntad por los artistas del primer Cinquecento, y la cuestión de la evocación poética, así como de la representación visual de la bella Galatea, que aparece como uno de los motivos centrales de la estética de esta época.

Antonia Tissoni Benvenuti, Carlo Vecce y Claudia Corfiati establecieron el papel de la erudición filológica de los humanistas en este renacer o, mejor dicho, en esta "remotivación» de una vieja forma literaria, primero en la corte de Ferrara -en el círculo de los discípulos de Guarino Veronese- y, luego, con la edición princeps del texto teocríteo (Milán, -1480), en las de Florencia y de Nápoles ${ }^{25}$. En Florencia, la recuperación de Teócrito permitió, entre otras cosas, bajo la pluma de Angelo Poliziano, la evocación de la bella Galatea en la estancia 118 de sus Stanze per la giostra, verdadera prefiguración, y posible modelo, de la imagen que de Galatea daría Rafael en su Triunfo de Galatea $(\sim 1512)$. A partir de los versos de Poliziano, de la recuperación del modelo de Teócrito y, por tanto, de la renovación de la lectura de Virgilio, la ninfa Galatea se convirtió en uno de los principales iconos de los inicios del Cinquecento, en que las academias entre Roma y Nápoles iban ideando el ideal de un nuevo clasicismo.

Otra fuente probable de la obra fueron los Eikones de Filóstrato, cuya ekphrasis de Galatea -que hace eco a las antes mencionadas pinturas antiguas- Rafael probablemente haya querido emular para recrear en la Villa Farnesina, una villa comparable con las de la Antigüedad ${ }^{26}$. En una carta que, según Ludovico Dolce, habría dirigido en 1514 a su amigo Baldassare Castiglione, Rafael describió el proceso de composición de su Galatea, belleza ideal concebida

24. Véase Roland Béhar, "In medio mihi Cesar erit”: Charles-Quint et la poésie impériale», e-Spania. Revue interdisciplinaire d'études hispaniques médiévales et modernes, n 6, 2012, http:// e-spania.revues.org/21140.

25. Véanse Antonia Tissoni Benvenuti, «La restauration humaniste de l'églogue: l'école guarinienne à Ferrare», Le genre pastoral en Europe du XV au XVIT siècle, Paris, Université de Saint-Étienne, 1980, pp. 25-34; id., «Schede per una storia della poesia pastorale nel secolo XV: la scuola guariniana a Ferrara», en Franco Alessio y Angelo Stella (eds.), In ricordo di Cesare Angelini. Studi di letteratura e filologia, Milano, Il Saggiatore, 1979, pp. 96-131; Carlo Vecce, "Un codice di Teocrito posseduto da Sannazaro», en Antonio Manfredi y Carla Maria Monti (eds.), Le antiche e le moderne carte. Studi in memoria di Giuseppe Billanovich, Padova, Antenore, 2007, pp. 597-616, e id., «Sannazaro e la lettura di Teocrito», La Serenissima e il Regno. Nel V centenario dell'Arcadia di Iacopo Sannazaro, Bari, Cacucci 2006, pp. 685-696, así como Claudia Corfiati, «Il fantasma di Teocrito», Cahiers de recherches médiévales et humanistes, no 25, 2013, http://crm.revues.org/13100.

26. Insiste de modo especial en la deuda de Rafael respecto al texto de Filóstrato David Rijser, Raphael's Poetics: Art and Poetry in High Renaissance Rome, Amsterdam, Amsterdam University Press, 2012, cap. IV. 
-como la Helena de Zeuxis-a partir de la selección de las más bellas mujeres ${ }^{27}$. Galatea es una belleza ideal, no un retrato. Se ha dudado de que Rafael fuera el autor de aquella carta. Según John Shearman, se habría de atribuir al mismo Castiglione, quien la inventaría hacia 1522 a modo de homenaje para su amigo desaparecido: la carta constituiría como un retrato intelectual del pintor papal ${ }^{28}$. De ser cierta, esta manipulación acercaría aún más la Galatea rafaelesca a Garcilaso, quien pudo conocer a Castiglione durante los últimos años de vida de este, cuando ostentó el cargo de nuncio papal ante la corte imperial en España, y cuando Garcilaso ya podría soñar con aquel ideal de belleza que, para él, como para todos los cortesanos de su tiempo, representaría la nueva belleza del Renacimiento italiano.

La interpretación de la Loggia di Galatea, dentro de la economía simbólica de la Villa Farnesina, resulta bastante difícil, al haber quedado inconclusa en el momento de la muerte del pintor así como de su mecenas, el banquero Agostino Chigi ${ }^{29}$. Se considera generalmente que Polifemo simboliza el amor ferino, y Galatea, el amor celeste, que el mismo cuadro evidencia en la medida en que Galatea no cae bajo las flechas de los cupidillos bajo la amenaza de las cuales se hallan los demás seres marinos de su entorno. La postura de la nereida enaltecida es la de la linea serpentinata, inspirada en la Leda de Leonardo da Vinci $^{30}$ y que se halla en otras figuras rafaelescas de índole religiosa, como su Santa Catalina de Alejandría. Con este movimiento, Galatea representa, de acuerdo con las lecciones del neoplatonismo de Marsilio Ficino, el rechazo del poder terrenal del eros y el giro hacia la contemplación de las ideas, del mundo

27. Se conoce por su edición de las Lettere di diversi eccellentiss. [imi] huomini raccolte da diversi libri tra lequali se ne leggono molte non piu stampate, con gli argomenti per ciascuna delle materie di che elle trattono, e nel fine annotationi e tavole delle cose piu notabili e utile de gli studiosi, Vinegia, appresso Gabriel Gioliti de Ferrari et fratelli, 1554, reed. 1559, pp. 227-228: «Signor conte. Ho fatto disegni in più maniere sopra l'invenzione di Vostra Signoria e sodisfaccio a tutti, se tutti non mi sono adulatori, ma non sodisfaccio al mio giudicio perché temo di non sodisfare al vostro. Ve gli mando. Vostra Signoria faccia eletta d'alcuno, se alcuno sarà da Lei stimato degno. Nostro signore con l'onorarmi m'ha messo un gran peso sopra le spalle. Questo è la cura della fabrica di San Pietro. Spero bene di non cadervici sotto, e tanto più quanto il modello ch'io n'ho fatto piace a Sua Santità, ed è lodato da molti belli ingegni. Ma io mi levo col pensiero più alto. Vorrei trovar le belle forme degli edificî antichi, né so se il volo sarà d'Icaro. Me ne porge una gran luce Vitruvio, ma non tanto che basti. Della "Galatea" mi terrei un gran maestro, se vi fossero la metà delle tante cose che Vostra Signoria mi scrive; ma nelle sue parole riconosco l'amore che mi porta, e le dico che, per dipingere una bella, mi bisogneria veder piu belle, con questa condizione: che Vostra Signoria si trovasse meco a far scelta del meglio. Ma, essendo carestia e di buoni giudici e di belle donne, io mi servo di certa idea che mi viene nella mente. Se questa ha in sé alcuna eccellenza d'arte, io non so; ben miaffatico di averla [...]».

28. Véase John Shearman, "Castiglione's portrait of Raphael», Mitteilungen des Kunsthistorischen Institutes in Florenz, vol. 38 no 1, 1994, pp. 69-97.

29. Para un recorrido crítico de esta quaestio vexata, véase, además de Beate Czapla, «Die Wandlung der Nereide Galatea...», art. cit., Christof Thoenes, "Zu Raffaels Galatea», en id., Opus incertum. Italienische Studien aus drei Jahrzehnten, München/Berlin, Deutscher Kunstverlag, 2002, pp. 51-116, e id., "Galatea, tentativi di avvicinamento", ibid., pp. 215-244.

30. Véase Konrad Oberhuber, Raffaello: L’opera pittorica, Milano, Electa, 1999, p. 170. 
de las cuales ella misma es una emanación. La disposición espacial de ambos cuadros ubicaba además al espectador cortesano en la posición de identificarse con Polifemo y de reducirse a una mera contemplación de las perfecciones de Galatea, encarnación de la idea de la belleza en el mundo ${ }^{31}$.

El Renacimiento tendió, pues, a ver en Galatea un ente ideal, como lo expresaría la carta de Rafael a Castiglione. Idea concebida por Poliziano y por Rafael, Galatea parece haberse convertido, más que cualquier otra ninfa del Cinquencento, en un icono, un referente inmediatamente reconocible en el imaginario y con valor estructurante para el campo intelectual que se reclama de él. Surgirían rápidamente copias, empezando por las numerosísimas interpretaciones grabadas, en especial de Marcantonio Raimondi. La imagen gozaría así de un creciente favor entre artistas, príncipes y poetas, hasta convertirse en un símbolo de la nueva manera de concebir el arte como lugar de la representación entre eros terrestre y eros divino. No sería, por cierto, el único: en los mismos años, probablemente inspirándose en los Asolani (1505) de Pietro Bembo, Tiziano diseñaría por su lado otra alegoría de las dos Venus, con Amor sagrado y Amor profano (hacia 1514), que ejercería una fascinación comparable en Italia así como en España ${ }^{32}$. Pero, con la herencia de los discípulos de Rafael, se daría con lo que la historia del arte suele llamar el manierismo, una fase de imitaciones intensas y de variaciones ingeniosas sobre el modelo del maestro que se convertiría en el signo distintivo de la época. En tiempos de Garcilaso irían a Nápoles artistas tan destacados como Cellini, Vasari y Polidoro da Caravaggio, alumno de Rafael que se halla a inicios de los años 1530 en Nápoles y luego en Mesina, donde participa en las obras para la acogida de Carlos V de Túnez, en 1535 -y poco antes de que el emperador llegara allí en su regreso a Nápoles, para el invierno-. En todos aquellos momentos, y desde los tiempos en que conocería a Castiglione, en 1526, Garcilaso llegaría a tener pleno conocimiento de la belleza visiva ideal de Galatea.

31. Para esta interpretación de la Galatea de Rafael, véase Ernst H. Gombrich, Nuevas visiones de viejos maestros. Estudios sobre el arte del Renacimiento IV, trad. Remigio Gómez Díaz, Madrid, Alianza, 1987, pp. 91 sqq.

32. Para la interpretación en clave neoplatónica de este cuadro, ahora conservado en la Galleria Borghese, véase el clásico ensayo de Erwin Panofsky, Tiziano. Problemas de iconografía, trad. I. Morán García, Madrid, Akal, 2003, pp. 115 sqq. Esta interpretación ha sido cuestionada más de una vez, en especial por Rona Goffen, «Titian’s Sacred and Profane Love: Individuality and Sexuality in a Renaissance marriage picture», Studies in the History of Art, vol. 45, 1993, pp. 121-132. Para una discusión más reciente, que muestra cómo la línea de Panofsky puede ser válida en cuanto el cuadro sigue representando la elección propuesta a la novia a punto de casarse entre el vicio y la virtud, véase Ross S. Kilpatrick, “Sorella sacra e sorella profana”: Revisiting with Ovid the Borghese Titian", International Journal of the Classical Tradition, vol. 6, no 1 , 1999, pp. 30-50. 


\section{Galatea, entre Pontano y Sannazaro}

Junto a la figuración visual de Galatea, llevada a cabo magistralmente por Rafael, es obligado disponer en paralelo la recreación poética de la nereida, gestada por los mismos años entre Roma y Nápoles ${ }^{33}$. A partir de los modélicos versos de Pontano y Sannazaro, la fortuna de la Galatea neolatina afecta de manera directa a la reconstrucción del contexto estético en el que se inscribe la égloga I de Garcilaso.

Entre los primeros artífices de la recuperación consciente a la par que jocosa del modelo de Teócrito figura el maestro de la academia humanística napolitana, Giovanni Pontano, quien otorgó a su Galatea un puesto de honor incluyéndola en su diálogo Antonius en compañía de otras composiciones cantadas por un viejo -trasunto dialogístico del maestro de Pontano, Antonio Beccadelli- en camino hacia a una boda que tendrá que alegrar con su canto: «Dulce dum ludit Galatea in unda...» ${ }^{34}$. El tono jocoso de la composición se acerca al de los versos fesceninos de las bodas. Llama la atención, como señala Jesús Ponce Cárdenas, la «inversión mítica» que lleva a cabo Pontano, al darle la palma del triunfo a Polifemo, y no a Galatea -en consonancia con versiones griegas del mito según las cuales el relato culmina con la conquista de Galatea por el jayán ${ }^{35}$ - Si bien esta versión del relato de la caza de Galatea abre obviamente perspectivas de lectura del mito muy distintas a las de la tradición idealizadora de Petrarca, Poliziano y de Rafael, constituye ante todo, según lo subraya Vera Tufano, un claro diálogo con el mismo Teócrito, cuyo idilio XI evocaba la frustración -superada en el texto de Pontano- de no disponer de un cuerpo que le permita alcanzar a Galatea en las aguas ${ }^{36}$.

Desde Nápoles, y de un modo más complejo que con el juego de su maestro Pontano, Iacopo Sannazaro iba a proponer una sutil y muy fecunda reescritura del idilio de Teócrito con teselas virgilianas, que combinaría las líneas de interpretación de la Antigüedad y del Renacimiento ${ }^{37}$. Sannazaro haría un uso

33. Los estrechos vínculos entre ambas ciudades resultan bien conocidos. Para un estudio reciente que arroja luz sobre la relación entre pintura y poesía en aquellos años, véase $\mathrm{D}$. Rijser, Raphael's Poetics..., op. cit.

34. Este poema encontraría durante el Siglo de Oro una adaptación en forma de soneto bajo la pluma de Agustín Calderón: «Mientras está en las aguas dulcemente, / con diestros brazos Galatea luchando / y sus desnudos pechos van cortando / el dichoso cristal de la corriente, / el viejo Polifemo, que la siente, / su cueva y sus cabrillas olvidando, / se arroja al agua y la siguió nadando / cual corre entre la grama la serpiente. / Fatigada la ninfa, al soberano / coro, contra el pirata embravecida, / huyendo favor pide; mas en tanto / el temerario gladiador anciano / triunfó de pecho y boca. Ella, corrida, / se desapareció resuelta en llanto (Cancionero antequerano, ed. José Lara Garrido, Málaga, Diputación de Málaga, 1988, p. 121).

35. Véase Jesús Ponce Cárdenas, El tapiz narrativo del Polifemo: eros y elipsis, Barcelona, Universitat Pompeu Fabra, 2010, pp. 42 sqq.

36. Véase Vera Tufano, "Il Polifemo del Pontano. Riscritture teocritee nella Lyra e nell'Antonius", Bollettino di studi latini, vol. 40, 2010, pp. 22-45, aquí p. 28.

37. Sobre Sannazaro lector de Teócrito, véase C. Vecce, «Un codice di Teocrito...», art. cit., 
recurrente del nombre de Galatea, que se convierte en un motivo continuo de sus Eclogx piscatoriæ. Ya en la primera Ecloga, recordaría a la bella nereida al final de una serie de figuras marinas asociadas con Proteo (vv. 84-90):

\author{
Hic tibi Nisaee et flavos resoluta capillos \\ Cymodoce mitisque pia cum matre Palaemon \\ Et Panope et Siculi custos Galatea profundi \\ Sollemnes nectent choreas et carmina dicent \\ Quae Proteus quondam divino pectore vates \\ Edocuit, magni cum funera fleret Achillis \\ Et Thetidis luctus consolaretur amaros. ${ }^{38}$
}

La imagen no distaba mucho de aquella del fresco de Rafael. Sería, sin embargo, en su segunda égloga, intitulada Galatea, donde Sannazaro ofrecería su principal reescritura del mito antiguo, con un sistema de múltiples referencias a la herencia antigua y a la poesía contemporánea ${ }^{39}$.

La situación enunciativa de la égloga recuerda aquella de la segunda bucólica de Virgilio -donde Coridón le reprocha su frialdad a Alexis-y la del undécimo idilio de Teócrito, que el mismo Virgilio había recordado en su novena bucólica como canto conocido de todos (v. 38: «neque est ignobile carmen»). Se recuerda cómo, a renglón seguido (vv. 39-43), Virgilio había adaptado los primeros

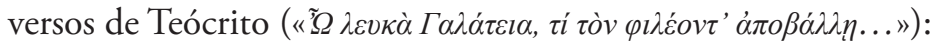

Huc ades, $O$ Galatea; quis est nam ludus in undis

hic ver purpureum; varios hic flumina circum

fundit humus flores; hic candida populus antro

imminet, et lentae texunt umbracula vites.

huc ades: insani feriant sine litora fluctus.

Como demostró Beate Czapla, Sannazaro reescribe a Virgilio, combinando los segmentos de la segunda y de la novena bucólica, así como otras numerosas teselas de la tradición poética. Abocado a la melancolía amorosa, como Polifemo en Teócrito y como Coridón en la bucólica II, el pescador Lycon eleva su canto desde la orilla del mar, de donde la bella Galatea ha huido, recriminándole su desaparición. El lugar de este canto es Mergellina, lugar de vida del mismo Sannazaro, en el borde de la bahía de Nápoles. La inspiración siciliana de Teócrito se convierte en un discurso ya no siciliano sino partenopeo.

e id., «Sannazaro e la lettura...», art. cit.

38. Jacopo Sannazaro, Latin Poetry, trad. Michael C.J. Putnam, Cambridge, Massachusetts y London, The I Tatti Renaissance Library, 2009, p. 108.

39. Sobre esta égloga, véase sobre todo a Beate Czapla, «Sannazaros zweite Ekloge Galatea als Neufassung eines non ignobile carmen (Verg. ecl. 9, 37-43)», en Eckart Schäfer (ed.), Sannazaro und die augusteische Dichtung, Tübingen, Gunter Narr, 2006, pp. 69-86, así como, para esta y para el conjunto de las Piscatoriæ, Carmelo Salemme, Il Canto del Golfo. Le Eclogæ piscatoriæ di Iacopo Sannazaro, Napoli, Loffredo editore, 2007. Véase también Liliana Monti Sabia, «Virgilio nelle Piscatoriæ di Iacopo Sannazaro», en Davide Canfora y Angela Caracciolo Aricò (eds.), La Serenissima e il Regno nel V Centenario dell'Arcadia di Sannazaro, Bari, Cacucci, 2006, pp. 501532. 
Immitis Galatea, nibil te munera tandem,

Nil nostrae movere preces? verba irrita ventis

Fudimus et vanas scopulis impegimus undas $[\ldots]^{40}$

Sigue la invitación hecha a Galatea por parte de Lycon a que contemple las aguas tranquilas del mar bajo la noche -cuadro inédito en la tradición que va de Teócrito a Virgilio y que marca la novedad de las Eclogæ piscatoriz ${ }^{41}$. En medio de esta nocturna soledad, permanece el pescador doliente ${ }^{42}$, cuyo dolor no puede ser achacado a las bellas jóvenes que pueblan con su presencia la bahía ${ }^{43}$, sino a la sola Galatea ${ }^{44}$. La cruel no acepta los regalos que Lycon le ha hecho, un millar de ostras, original reinterpretación de los obsequios del Polifemo teocríteo ${ }^{45}$. Y, llegando a la cumbre de la égloga, Sannazaro menciona el mayor de los regalos posibles, una lana que le dio Meliseus -símbolo de la inspiración poética-:

Quid refugis? Tingenda tibi iam lana paratur
qua niteas superesque alias, Galatea, puellas,
lana maris spumis quae mollior. Hanc mihi pastor
ipse olim dedit, hanc pastor Melisaeus, ab alta
cum me forte senex audisset rupe canentem,
et dixit, "Puer, ista tuae sint praemia Musae,
quandoquidem nostra cecinisti primus in acta".
Ex illo in calathis servavi, ut mittere possem.
Sed tu (ne qua miti superet spes, ne qua futuri
condicio, Galatea) manum mibi dura negasti. ${ }^{46}$

Meliseus -es decir, Pontano- le ha destinado a Lycon -Sannazaro- la lana para tejer sus cantos, que el triste pescador quiere ahora ofrecer a su bella amada, demostrando cómo su poesía debe ir dirigida a Galatea. No sirven las comparaciones mitológicas: Lycon queda prendido en las redes mortíferas de

40. J. Sannazaro, Latin Poetry, op. cit., p. 112.

41. Ibid.: "Aspice, cuncta silent, orcas et maxima cete / somnus habet, tacitae recubant per litora phocae, I non Zephyri strepit aura, sopor suus umida mulcet / aequora, sopito connivent sidera caelo...».

42. Ibid.: «Solus ego (ei misero) dum tristi pectore questus / nocte itero, somnum tota de mente fugavi, I nec tamen ulla meae tangit te cura salutis».

43. Ibid.: "At non Praxinoe me quondam, non Polybotae / filia despexit, non divitis uxor Amyntae, / quamvis culta sinu, quamvis foret alba papillis. I quin etiam Aenaria (si quicquam credis) ab alta / saepe vocor; solet ipsa meas laudare Camenas I in primis formosa Hyale cui sanguis Iberis / clarus avis, cui tot terrae, tot litora parent / quaeque vel in mediis Neptunum torreat undis».

44. Ibid., pp. 112-114: "Sed mihi quid prosunt haec omnia, si tibi tantum / (quis credat, Galatea?) tibi si denique tantum / displiceo? si tu nostram crudelis avenam / sola fugis, sola et nostros contemnis amores?».

45. Ibid., p. 114: «Ostrea Miseni pendentibus eruta saxis / mille tibi misi, totidem sub gurgite vasto / Pausilypus, totidem vitreis Euploea sub undis / servat adhuc; plures Nesis mihi servat echinos / quos nec vere novo foliis lentiscus amaris / inficit aut vacuae tenuant dispendia Lunae. / Praeterea mihi sub pelago manus apta legendis / muricibus; didici Tyrios cognoscere succos / quoque modo plena durent conchylia testa».

46. Ibid. 
su deseo por Galatea y experimentará el naufragio en el piélago ${ }^{47}$. Considera -así como lo hará Salicio en la égloga de Garcilaso- la eventualidad del exilio, para abandonar el lugar en que se halla, pero recuerda que no por ello se deshará de la aflicción:

Heu quid agam? Externas trans pontum quaerere terras

iam pridem est animus, quo numquam navita, numquam

piscator veniat: fors illic nostra licebit

fata queri. Boreae extremo damnata sub axe

stagna petam et rigidis numquam non cana pruinis

an Libyae rapidas Austrique tepentis harenas.

et videam nigros populos Solemque propinquum?

Quid loquor infelix? an non per saxa, per ignes,

quo me cumque pedes ducent, mens aegra sequetur?

Vitantur venti, pluviae vitantur et aestus,

non vitatur amor; mecum tumuletur oportet. ${ }^{48}$

Non vitatur amor: no se escapa al amor. Misérrimo, se ve abocado al suicidio de amor, para el cual invoca la compasión de la ninfas:

Iam saxo meme ex illo demittere in undas praecipitem iubet ipse furor. Vos o mihi Nymphae,

vos maris undisoni Nymphae, praestate cadenti

non duros obitus saevasque exstinguite flammas.

Scilicet haec olim, veniens seu litore curvo

Caietae, seu Cumarum navalibus altis,

dum loca transibit, raucus de puppe magister

hortatus socios "Dextrum deflectite» dicet

«in latus, o socii, dextras deflectite in undas;

vitemus scopulos infames morte Lyconis». ${ }^{49}$

La muerte de Lycon deberá servir, al menos, de ejemplo a la posteridad, para que se evite una pasión tan desdichada como la que nutre por la dura Galatea. Y la égloga se cierra con la vuelta de la voz exterior del poeta, parecida a la del poema de Garcilaso, que había presentado la dedicatoria y que cierra también el canto luctuoso de Salicio con una estrofa (vv. 225: «Aquí dio fin a su cantar Salicio...»):

Talia nequiquam surdas iactabat ad auras infelix piscator et irrita vota fovebat,

47. Ibid.: «Hoc est, hoc, miserum quod perdidit. Ite Camenae, / ite procul; sprevit nostras Galatea querelas. I Scilicet (exiguae videor quod navita cymbae. I quodque leves hamos nodosaque retia tracto) / despicis. An patrio non hoc quoque litore Glaucus / fecerat, aequoreae Glaucus scrutator harenae? / Et nunc ille quidem tumidarum numen aquarum. / Sed nec (quae nimium vel me sic falsa fatigat) / fabula te moveat Lydae, licet illa puellis / Iactet nescio quas mibi se misisse corollas; I non me Lyda tamen, non impulit, aequora testor / Nereidasque omnes. Si fallo, naufragus illas / experiar salsosque bibam sub gurgite fluctus».

48. Ibid., p. 116.

49. Ibid. 
cum tandem extremo veniens effulsit ab ortu

lucifer et roseo perfudit lumine pontum. ${ }^{50}$

El canto concluye, pues, con la imagen de la aurora rosácea que asoma en el oriente, leve nota de esperanza. En Garcilaso, toda la égloga tiende en cambio hacia la plena luz del sol y paulatinamente se va sumergiendo, luego, en la oscuridad de la noche ${ }^{51}$.

Garcilaso imita de varios modos los versos de Sannazaro, en la égloga I y en otras partes de su obra ${ }^{52}$. En especial, construye el recuento de los regalos despreciados de Salicio para Galatea en un modo semejante al de Virgilio, pasando acto seguido, mediante la figura de Títiro, a la evocación del poeta latino (vv. 169-174):

\footnotetext{
Siempre de nueva leche en el verano y en el invierno abundo; en mi majada

la manteca y el queso está sobrado.

De mi cantar, pues, yo te via agradada tanto, que no pudiera el mantüano

Títero ser de ti más alabado.
}

La crítica ha visto en este pasaje ante todo, y con razón, una reescritura de Virgilio, bucólica II (vv. 22-27: «Lac mihi non...»), a su vez una reescritura de Teócrito, XI, 36-37, con alguna reminiscencia de Sannazaro (Arcadia, IX, 41), que a su vez retoma el texto de Virgilio ${ }^{53}$. Pero es necesario notar, con Beate Czapla, que este pasaje de Virgilio constituía precisamente la matriz de la reescritura que Sannazaro propone con su Galatea. Él mismo comentó el pasaje de Virgilio en una célebre carta de 1521 a Antonio Seripando, subrayando su -relativa- inferioridad respecto al original de Teócrito: «Dice Virgilio: Lac mihi non aestate novum, non frigore desit; il loco, donde lo piglia da Theocrito, dice tutti li quattro tempi; non credo che fusse elettione ma non potere [...] ${ }^{54}$. Colocó así estos versos imitados, tanto en su Arcadia como en sus Eclogx, en el centro de las discusiones entre sus discípulos, entre los cuales figuraría indirectamente Garcilaso, gran amigo de Girolamo Seripando, hermano de Antonio y heredero de su biblioteca.

Justo después del catálogo de bienes ofrecidos a Galatea, motivo marcadamente retomado por Sannazaro de Virgilio, la inclusión de la figura del

\section{Ibid.}

51. Sobre el ritmo solar de la égloga I, véanse los artículos ya mencionados de C. Segre, «Análisis conceptual...» y P. Cordoba, «Sous le signe de Diane...».

52. Sobre Garcilaso imitador de Sannazaro, véase, con bibliografía, Roland Béhar, «Virgilio, san Agustín y el problema del poema heroico cristiano (1520-1530)», Criticón, no 107, 2009, pp. 57-92, http://cvc.cervantes.es/literatura/criticon/PDF/107/107_057.pdf

53. Véase Iacopo Sannazaro, Arcadia, ed. Carlo Vecce, Roma, Carocci Editore, 2013, p. 206: "Et acciò che chi egli è occolto non ti stia, mille pecore di bianca lana pasce per queste montagne, né di state né di verno mai li manca novo latte».

54. Iacopo Sannazaro, Opere volgari, ed. A. Mauro, Bari, Laterza, 1961, p. 379, citado por C. Vecce, «Un codice di Teocrito...», art. cit., p. 613. 
poeta de quien el pastor o el pescador heredó su estro poético -en Sannazaro, Pontano (pero presentado en otro poema como heredero tanto de Teócrito como de Virgilio); en Garcilaso, Virgilio- también parece ser un rasgo que Garcilaso, en su reescritura del pasaje virgiliano, retomara de la égloga Galatea del maestro napolitano. Semejante procedimiento de imitación compuesta, de enriquecimiento de la reescritura de Virgilio mediante reminiscencias de reescrituras sannazarianas del vate de Mantua, ya se puede observar en la dedicatoria del inicio de la égloga $\mathrm{I}^{55}$. No sorprende, pues, constatar que Garcilaso lo repita una y otra vez ${ }^{56}$.

Sannazaro retoma una tercera vez aún el tema de Galatea, en la quinta y última de sus Eclogæ piscatoriæ, cuya segunda parte reproduce el canto que expresa el amor desesperado de Telgón por Galatea, quien ha dejado de quererlo y que lo induce a buscar la muerte en el agua -de modo semejante al Salicio de la égloga I, pero también al Albanio de la égloga II-. En su Ecloga, Sannazaro ponía en la boca de Telgón las palabras que Virgilio había consignado en su bucólica IX (v. 38), "Huc ades...», a modo de clarísima reminiscencia y de señal de que el amador infeliz siempre es, en la bucólica, una reescritura del cíclope teocríteo. No cabe duda de que Garcilaso haya tenido en mente ambas composiciones sannazarianas a la hora de concebir las suyas.

\section{Galatea y los Émulos de Sannazaro}

La égloga Galatea de Sannazaro no se ha de considerar como una más en una larga serie de variaciones sobre el mito de Galatea. Resulta ser la más personal de las del poeta napolitano, ya que, en su mismo centro, el poeta se presenta a sí mismo como el heredero del maestro de la Academia napolitana, Pontano, lo cual hace de él el máximo exponente de la nueva escuela poética que reivindica la herencia de Virgilio en la Italia de los inicios del Cinquecento. Basta mencionar el juicio admirativo de Julio César Escalígero, cuyos Poetices libri septem (1561), publicados de modo póstumo, consagrarían la importancia de Sannazaro: el conjunto de las églogas marinas de Sannazaro hace del napolitano, único entre todos, el digno heredero de Virgilio, pero la segunda de estas, Galatea, le parece con diferencia la mejor ${ }^{57}$. Si bien se publicaría tan solo en 1526, esta égloga circulaba en manuscritos ya ańos antes, lo cual le permitiría a Escalígero conocerla entre 1515 y $1519^{58}$.

55. Véase R. Béhar, “"Tu mihi”: variaciones bucólicas...», art. cit.

56. Se trata en realidad de un tipo de imitatio que también se puede llamar contaminatio y que Daniel Javitch, a propósito del Orlando furioso ha descrito como imitación de imitación; véase D. Javitch, «The Imitation of Imitations in Orlando Furioso», Renaissance Quarterly, $\mathrm{n}^{\circ} 38$ 2, 1985, pp. 215-239.

57. Véase Julius Cæsar Scaliger, Poetices libri septem, Lyon, apud Antonium Vincentium, 1561 (lib. VI), p. 315, col. a: "In carmine quoque pastorali solus legi dignus omnium qui post Virgilium scripsere.» Y: "Ecloga vero Galatea longe optima est».

58. Es de mencionar, además, la existencia de dos ejemplares de las Eclogæ fechados no en 
El texto de Sannazaro destaca justamente por lo que se distancia de Teócrito y de Virgilio y, con la misma, se vuelve digno de ser comparado con ellos. Alberga, pues, una consistente novedad. Debe ser considerado desde la perspectiva de un movimiento más amplio de reescrituras más tópicas y, a menudo, más ovidianas, del mito de Galatea. Con su De Fauno et Galatea, Pietro Bembo hace eco no tanto a Teócrito, como a Ovidio, con la salvedad de que Polifemo queda suplantado por un fauno:

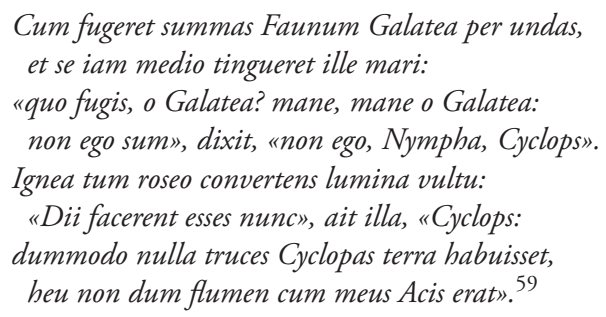

El fauno pretende conquistar a Galatea arguyendo que no es un temible cíclope y que merece su atención, mas la bella nereida le devuelve el argumento y lamenta que no lo sea, porque entonces su querido Acis hubiera podido escapar de la furia celosa de Polifemo. Como demostró Françoise Lavocat, Bembo asienta con este epigrama la fortuna de la identificación renacentista entre los faunos y el cíclope en cuanto seres reconocibles por su lascivia ${ }^{60}$ : esta lectura sigue, de nuevo, la opción idealizadora que fue probablemente la que predominaría en la Roma de inicios de Cinquecento y que hace de Galatea, ante todo, el símbolo del eros celeste. Otros poetas variarían el mito de Galatea durante las primeras décadas del Cinquecento. Especial mención sobre el tema merecerían los poemas de Girolamo Fracastoro (Carmina, VII, Carpe fugam, Galatea; ferus petit aequora Cyclops) y de Marcantonio Flaminio (Carmina, IV, 5, Cur subito, fons turbidule, tuus humor abundat?). Más cercanos al pasaje garcilasiano, y cuyos versos se puede suponer que conoció, son de citar Antonio Tilesio y Giano Anisio, en Nápoles, y Nicolas Bourbon, en Francia. $\mathrm{Al}$ menos para los dos primeros, hay constancia de que Garcilaso los conoció personalmente.

El poema de Giano Anisio (ca. 1470-ca. 1540), la égloga Ursus, publicada en los Ianii Anysii Varia poemata et satyrae. Ad Pompeium Columnam cardinalem (Nápoles, 1531), presenta el relato de Polifemo y Galatea insertado en una trama bastante compleja. Según Tobia R. Toscano, se ha de considerar 1513

1526, año teórico de la edición princeps, sino en 1520, pudiéndose tratar de una edición pirata. Véase Nicholas Smith, «The Genre and Critial Reception of Jacopo Sannazaro’s Eclogæ Piscatoriæ (Naples, 1526)», Humanistica Lovaniensia. Journal of Neo-Latin Studies, n 50, 2001, pp. $199-$ 219, aquí pp. 205-206.

59. Pietro Bembo, Lyric Poetry. Etna, ed. Mary P. Chatfield, Cambridge, Massachusetts y London, The I Tatti Renaissance Library, 2005, p. 108.

60. Véase Françoise Lavocat, La Syrinx au bûcher: Pan et les satyres à la Renaissance et à l'âge baroque, Ginebra, Droz, 2005. 
como término ante quem de la redacción de la égloga. En efecto, 1513 es el ańo del casamiento -anunciado en el texto- del destinatario de la égloga, Enrico Orsini («Ursus»), con Maria Sanseverino ${ }^{61}$. Junto a Ursus, aparecen en la égloga Ianus y Mycon, a quien Ursus y Ianus invitan, durante una pausa en su peregrinación, a que cante de nuevo un poema que le ha permitido vencer poéticamente a otro pastor, Lycidas, en quien se puede reconocer al propio Sannazaro. El objeto de este canto es el mito de Polifemo y Galatea. Cítense tan solo los primeros versos de este relato intercalado en la pastoral:
Audite, \& nostrum penitus cognoscite carmen.
Plus solito incaluit quondam Polyphemus amore,
illo saepe die Galatea fefellerat, undis
se totam exertans, risuque ad gaudia amantem
invitans, ridente illa, ridebat olympus.
At liquidum pectus Polyphemi, tabe fluebat.
Quum tandem fugiens pelago se gurgite mersit,
et suspirantem media spe liquit amantem.
His sequitur pastor fugientem uocibus ardens,
immo haec infelix iactabat inaninus auris. ${ }^{62}$

Sigue la queja del cíclope, la cantilena Cyclopis, para llamarla con los términos antiguos:

Heu Galatea fugis, Galatea fugis, mea vita

cur Galatea fugis? saltem hec tibi munera donem,

munera iampridem tibi que servata ferebam.

Heu fugit, immiti ponto atque immitior curis.

Aspice, contemnit qua munera, sape Melenis

conata est pulchra has pulchras abducere vulpes,

et demum abducet. Speo facere omnia prompta,

quid non experta est lepido hoc pro turture? in ore

pascitur, inque manu, \& cantu vel acanthida vincit.

O quoties Galatea tibi de lacte recenti

caseus est factus, dura es, induruit ille.

o quoties Galatea tibi servavimus hoedos,

creverunt hoedi, crevit mihi flamma medullis.

An quia sim pauper spernis me nympha? quis unquam

tam dives pecoris, tam pinguis casei abundans.

An quia sim turpis? nuper me in littore vidi,

dum mare marmoreum turbarent flamina nulla.

61. Véase Tobia R. Toscano, «Giano Anisio tra Nola e Napoli. Amicizie, polemiche e dibatti», en id., L'enigma di Galeazzo di Tarsia. Altri studi sulla letteratura a Napoli nel Cinquecento, Napoli, Loffredo Editore, 2011, pp. 79-102, aquí pp. 92-94, así como su artículo en este mismo volumen del Bulletin hispanique. En ambos trabajos se distancia de la propuesta de Carlo Vecce («L'egloga Melisaeus di Giano Anisio tra Pontano e Sannazaro», en Stefano Carrai (ed.), La poesia pastorale nel Rinascimento, Padova, Antenore, 1998, pp. 213-234, p. 217) de identificar a Ianus con el humanista Aulo Giano Parrasio, para ver en Ianus y en Mycon dos aspectos del propio Ianus Anisio.

62. Ianii Anysii Varia poemata et satyrae. Ad Pompeium Columnam cardinalem, Neapoli, per Ioannem Sultzbacchium Hagenouensem Germanum, 1531, fol. $74 \mathrm{r}^{\circ}$. 
Non barba hac pulchra est, ciliumque hoc? non ita pulchro vere nitent virides prolixo gramine rupes.

Hoc oculo, solis nitido cum sydere certo. ${ }^{63}$

La pretensión -excesiva, sin duda- de haber vencido a Lycidas-Sannazaro ("quis olim vicit Lycidam, qui e montibus oscis / huc venit, cantu \& calamis certare paratus») sugiere un vínculo de emulación de esta égloga con la segunda de Sannazaro, Galatea. Parece difícil determinar las condiciones históricas concretas a las que se refiere. ¿Alude a algún concurso poético en el que habría vencido Anisio? Apunta en todo caso al hecho de que pudo haber una rivalidad -amistosa- entre Anisio y Sannazaro, precisamente en torno a la recreación poética de la figura de Galatea.

En esta emulación poética, Anisio vuelve a acercarse más al modelo de Virgilio. Lo interesante es que el texto de Anisio ofrece algunos puntos de contacto con el discurso del Salicio garcilasiano, en especial con los versos 169-182:

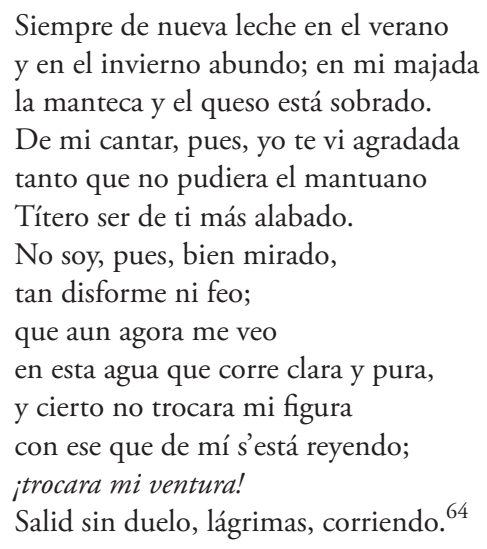

Estas coincidencias entre Anisio y Garcilaso, quien según toda probabilidad conoció la égloga de Anisio publicada en 1531 -pocos meses antes de su llegada a Nápoles-, se deben, sin embargo, tanto a este conocimiento como al hecho de que ambos siguen la pauta marcada por Virgilio, concretamente los famosos versos 25-26 de la bucólica segunda -en los que, según el juicio de Julio César Escalígero (Poetices libri septem, lib. V), Virgilio igualaría a Teócrito-: "Nec sum adeo informis: nuper me in littore vidi, / Cum placidum ventis staret mare».

Es posible, pues, rastrear las huellas de un verdadero juego de variaciones sobre el motivo virgiliano, probablemente lanzado por el magisterio de Sannazaro, y que encontraría también ecos fuera de la Italia de Garcilaso. Sirva tan solo a modo de ejemplo el breve poema jocoso de Nicolás Bourbon ( $c a$. 1503-ca. 1550) Ad puellam. E graeco suo, publicado por primera vez en las

63. Ibid., fol. $74 \mathrm{v}^{\circ}$.

64. G. de la Vega, Obra poética..., op. cit., pp. 134-135. 
Nugae de 1533, que desarrolla ciertos aspectos que ya se hallan en Virgilio y en Anisio:

Prae te non duri montes, non robora dura, durior est glacies pectore nulla tuo.

Non adamas prae te durus, non marmora dura, duritiem vincunt nulla metalla tuam.

Sis quam dura voles, certe moriere, cinisque

fies, o virgo mitior ergo veni.

Non sum adeo informis, quin sim te dignus, amica:

in speculo formam cogor amare meam.

Oscula da centum, da circum brachia collo,

sim tuus, et mea sis: accipe daque fidem.

Quem fugis? Ah demens, cur membra decora juventae, cur etiam sordent munera nostra tibi?

Dura manes? Aliam inveniam, quae carmine nostro clara erit, at sero facta dolebis anus. ${ }^{65}$

Bourbon se aleja de la seriedad elegíaca del texto de Sannazaro y vuelve, como lo hiciera Pontano, a la meditación del tono jocoso de Teócrito. El carpe diem del último verso, que retoma los versos de Teócrito XI, 72-76, anuncia el famoso poema de Ronsard Quand vous serez bien vieille... El motivo se asocia aquí con la capacidad del verbo poético de eternizar la fama de la amada -según el tópos ya observado en relación con la Galatea de Petrarca-.

Otros motivos vinculan entre ellos los textos de Garcilaso, de Anisio y de Bourbon, demostrando el que todos se inscribían en un mismo juego de imitaciones. Uno especialmente llamativo es el de la dureza de la amada, que Garcilaso, con su primer verso "Oh más dura que mármol a mis quejas...", pondría en el centro de la querella amorosa de Salicio. Mientras Anisio se limita a afirmar la dureza («dura es»), así como lo hiciera Sannazaro (v. 48: «manum mihi dura negasti»), Bourbon acumula las hipérboles para describir a la puella que no accede a sus deseos: su dureza es superior a la de los montes, de la encina, del hielo, del diamante, del mármol y de cualquier metal. Obviamente, la duritia es un topos de la poesía elegíaca y petrarquista, como lo muestra el uso de la misma imagen por el poeta napolitano Girolamo Angeriano en el poema De Caeliae duricie de su Erotopaegnion (Florencia, 1512):

Sunt duri scopuli, sunt dura et marmora, durum

et ferrum, in summis dura robora ingis

sunt dure rupes, sunt antra et cornua dura

65. Nugae, Basilea, Cratander, 1533, fol. G3vº citado según la edición crítica: Nicolas Bourbon, Nugae - Bagatelles (1533), ed. Sylvie Laigneau-Fontaine, Genève, Droz, 2008, p. 578. La mención «E greco suo», en el título, indica que se trata de un epigrama en latín que traduce otro del mismo Bourbon en griego -todos sus epigramas griegos se han perdido-. Véase ibid., p. 175. 
atque adamas durus, durum hyemale gelu.

Durior at scopulis mea Caelia, marmore, ferro,

robore, rupe, antro, cornu, adamante gelu. ${ }^{66}$

Aunque sea difícil una demonstración definitiva, resulta posible, si no probable, que el sintagma garcilasiano «más dura que mármol» sea un recuerdo de los versos de Angeriano ("Durior... mea Calia, marmore..."), directo o indirecto - dadas a la vez la difusión de la poesía de Angeriano en los ámbitos poéticos napolitanos, y la índole tópica de la expresión- ${ }^{67}$.

Otro poeta de la órbita sannazariana fue Antonio Tilesio, por el que sentía Garcilaso gran admiración, plasmada en la segunda de sus odas latinas, $\mathrm{Ad}$ Thylesium, escrita antes de la muerte del italiano en 1534, es decir al mismo tiempo que la égloga ${ }^{68}$. Tilesio había compuesto años antes una Galatea, que ya figuraba en los Poemata (Roma, in aedibus F. Minitii Calvi, 1524). Sin embargo, el poema se volvería a publicar en Zurich (Poemata. Cyclops et Galatea, Tiguri, ex aedibus Christophori Froschouer, 1531, reed. en 1537), lo cual demostraba su temprano éxito más allá de los límites de la península italiana y hacía que Garcilaso, al llegar a Nápoles en 1532, considerara esta pieza poética como una novedad digna de interés.

66. Girolamo Angeriano, Erotopaegnion, ed. Allan M. Wilson, Nieuwkoop, De Graaf Publishers, 1995, p. 92.

67. Se analiza la recepción e imitación del modelo neolatino de Angeriano entre los poetas españoles en J. Ponce Cárdenas, La imitación áurea, op. cit., pp. 78-83. Entre otros poemas, figura el «Sunt duri scopuli...» vertido al castellano en un soneto de Pedro de Padilla (pp. 7980). No sorprende, pues, que esta línea de la duritia haya calado más directamente en un amigo de Padilla, Miguel de Cervantes, cuya Galatea retoma abundantemente el "Oh más dura que mármol» garcilasiano, a veces de modo directo (en especial en las quejas de Lenio, en el libro VI, donde el verso se convierte en estribillo que cierra cada octava), y a veces con variaciones como esta, en el canto de Marsilio del libro III: «Más sorda a mi lamento, / más implacable y fiera / que a la voz del cansado marinero / el riguroso viento / que el mar turba y altera / y amenaza a la vida el fin postrero; / mármol, diamante, acero, / alpestre y dura roca, / robusta, antigua encina, / roble que nunca inclina / la altiva rama al cierzo que le toca: / todo es blando y suave, / comparado al rigor que en tu alma cabe» (Miguel de Cervantes, La Galatea, ed. Francisco Escobar, Flavia Gherardi y Juan Montero, Madrid, Real Academia Española, 2014, p. 180). La crítica ha destacado en esta serie el uso del italianismo «alpestre», pero cabe notar, también, que la serie «mármol, diamante, acero, / alpestre y dura roca, / robusta, antigua encina, / roble que nunca inclina» deriva de Angeriano o de Bourbon, y más probablemente de este último, donde se hallan las dos series de tres, pero en sentido inverso: montes, robora y glacies -el único elemento eliminado y cambiado por la encina-, y luego adamas, marmora, metalla. Sobre la presencia del verso de Garcilaso en la Galatea de Cervantes, véase Edward Dudley, «" $; \mathrm{O}$ más dura que mármol a mis quexas!": Presencia intertextual de Garcilaso en La Galatea de Cervantes», en Francisco La Rubia-Prado (ed.), Literatura y pensamiento en España: Estudios en honor de Ciriaco Morón Arroyo, Newark, Juan de la Cuesta, 2003, pp. 15-32.

68. Sobre Garcilaso y su relación con Tilesio, véase Eugenia Fosalba, «Sobre la relación de Garcilaso con Antonio Tilesio y el círculo de los hermanos Seripando», Cuadernos de filología italiana, vol. 19, 2012, pp. 131-144, http://revistas.ucm.es/index.php/CFIT/article/ view/41297. Para la oda a Tilesio, véase G. de la Vega, Obra poética..., op. cit., pp. 251-257. 
Desde los primeros versos, el poema anuncia una tonalidad original, debida al hecho de que Eco haya respondido a las quejas de Polifemo en el bosque, y que este le conteste, creyendo que se trata de Galatea y reprochándole su crueldad:

Quid mecum quereris, vel me magis improba rides,
garrula, vocalis, mima, diserta, loquax?
Qua mihi nulla videris opacis abdita sylvis,
sed mea dicta refers assona, nulla licet.
Iam satis ô Galatea superque iocosa fuisti,
ludere quin ludum desinis insolitum?
Quin profers formosa caput, latebrasque relinquis,
in que sinu recubantem ambitiosa foves?
Irritas lasciva, meum iecur astuat ardens.

Más adelante, vuelve a dirigir semejantes calificaciones a la dura ninfa, lo cual desencadena de nuevo el cruel juego del eco:

Dura, proterva, procax, petulans, qua illudis amantem, quo trepidas? Nullum iam datur effugium.

Nimirum densis latet hic sub montinus, ite, ite canes. rursus rettulit ite canes.

Certum est per saltus perquirere sicubi se abdit. Ite canes. Latrat hic, non minus illa latrat. ${ }^{70}$

La composición de Tilesio se caracteriza por la relativa libertad con que trata el motivo de las quejas de Polifemo, que renueva merced a la ingeniosa inserción del tema del eco, que le permite duplicar la palabra y hacer redoblar de ira al cíclope. De este modo, no se trata de un ejercicio de imitación stricto sensu, sino más bien de una recreación jocosa sobre un tema que ya empezaba, ahí por los ańos 1520, a ser fatigado por las repetidas imitaciones de los émulos de Sannazaro. Y, si bien no se dejan rastrear huellas de imitación directa de la Galatea de Tilesio por Garcilaso, es más que probable que la misma elección del tema haya podido despertar en el toledano el deseo de competir a su vez con los modelos ofrecidos por Teócrito, Virgilio, Sannazaro e incluso Anisio, pero insertando su imitación en una égloga de inspiración claramente cortesana.

\section{Galatea cortesana: Valenziano, Tansillo y el Cinquecento napolitano}

De por sí, el juego imitativo reconocible en la escritura de la églogas de Garcilaso, a veces obvio y a veces solo probable, demostraría el virtuosismo del artista, la necesaria sprezzatura que se requiere del cortesano. En la cadena de imitaciones en torno a una figura que alberga en alto grado posibilidades

69. Antonii Thylesii Consentini Poemata, Cyclops et Galatea, Tiguri [Zúrich], ex ædibus Christophori Froschouer, 1531, fol. [A6] $\mathrm{r}^{\circ}$.

70. Ibid., fol. [A7] $\mathrm{r}^{\circ}$. 
de interpretación éticas y filosóficas como lo es Galatea, desde su reinvención romana y napolitana en torno a 1500, este juego desempeña, sin embargo, otras funciones, cuyo estudio arroja nueva luz sobre la composición de la églogas de Garcilaso y, más en concreto, de la égloga I.

En efecto, según se ha visto, la figura de Galatea aparece, desde su encarnación bajo el pincel de Rafael, en los ańos 1510-1511, como posible icono de la filosofía neoplatónica, que circulaba entonces en los círculos cortesanos y a la que Castiglione había otorgado un lugar esencial en su Cortesano (1528), que Garcilaso estaría leyendo y, en parte, traduciendo, durante los años en que llegaría a Nápoles y compondría sus églogas, ya que va revisando la traducción del Cortesano por Juan Boscán (publicada en 1534). La égloga Galatea de Sannazaro, cuya fecha de escritura exacta se ignora pero de la que se sabe, por Escalígero, que ya estaba escrita hacia 1515, constituiría una primera y muy sonada respuesta poética a este proyecto, a la que otros ingenios poéticos contestarían después. Entre ellos figuran, y con un entramado que quedaría por establecer con mayor claridad, no solo Anisio y Tilesio, en Nápoles, y Bembo, Fracastoro y Flaminio, en un círculo italiano más amplio, sino también poetas que compusieron sus poemas en volgare.

Un ejemplo significativo de ello sería el piamontés Luca Valenziano, cuyas Opere volgari se publicaron en Venecia en 1532, gracias a los buenos oficios de un noble napolitano, Federico de Gervasio, quien dedicaría el poemario "A la nobile et virtuosa Madonna Meridiana Avanza». En esta publicación, que dio a conocer a una escala más amplia textos ya escritos décadas antes, es de mencionar un Atto pastorale en dos partes, donde aparece como figura central una pastora, o ninfa, llamada Galatea. Los versos no son de calidad excepcional, pero el primer Atto pastorale ofrece una configuración interesante. Un primer pastor, Licano, descubre a Galatea dormida y se siente arder de amor por ella. Galatea lo reconoce como poeta famoso por sus versos:

Sei tu Lican, di cui per fama è certo che de' greggi può dar larga dottrina, del suono amico, e de le rime esperto? ${ }^{71}$

Licano responde:

Quel son, ma il Cielo ancor non mi destina pastor si grande, né poeta raro, benché rime si batta in mia fucina. Vero è chél viso tuo nobile e chiaro alzar potrebbe il pastorale ingegno, e presto farmi con virtù preclaro. ${ }^{72}$

71. Opere volgari di M. Luca Valentiano Derthonese, Venegia, Bernardino di Vitulli Venetiano ad instantia di Federico de Gervasio Napolitano, 1532, fol. K i v ${ }^{\circ}$.

72. Ibid. 
Sigue un diálogo entre ambos, en el que él describe con elocuencia su amor y ella protesta con virtud, pero reconociendo que siente cierta atracción por el pastor, que sabe declarar sus pensamientos con tanto ingenio. En el momento en que Licano se dispone a partir, para demostrar en el mundo la virtud que lo hará digno del amor de Galatea, surgen otros dos pastores, Sincero y Titiro, igualmente enamorados de Galatea. Le recuerdan a la bella pastora su pasión, a lo cual ella responde:

\author{
Qualunque per amar sospira e geme, \\ protervamente la sua donna brama, \\ ch'amaro frutto vien di cotal seme. \\ Ma chi più onestamente onora et ama \\ la grazia e la virtù di donna grata, \\ non è la vita sua per questo grama. \\ Or, se da voi son drittamente amata, \\ a tutti vi fia egual quella dolcezza \\ che da cortese amor al cor vien data. \\ Però lasciate gli odii, e la fierezza \\ che i cuori vostri in le contese indura, \\ chognun può haver quel ch'onestate apprezza. \\ Amate pur, non dico mia figura, \\ ma quel che dà piacer senza vergogna, \\ d'appresso, da lontano e senza cura. \\ Hor io vi lascio, ch'a me andar bisogna \\ a la gran caccia, ove shonora il forte, \\ et si dà biasmo a chi con l'arco sogna. ${ }^{73}$
}

Este discurso de Galatea se puede entender, creemos, como la puesta en forma poética del dispositivo del programa de la Loggia di Galatea de la Farnesina: como una demonstración de la superioridad del amor honesto sobre los amores deshonestos, con la identificación de Galatea como personificación de la virtud ideal, adorada por todos los seres - pastores, pescadores u otros- que llegan a conocerla. El resto de la égloga muestra cómo Sincero y Titiro acabarán renunciando, ante la evidente virtud de Licano. La égloga de Valenziano, que pudo ser conocida en Nápoles e incluso por Garcilaso, confiere una forma eglógica y, por tanto, cortesana al programa neoplatónico, en un modo mucho más explícito, o menos sutil, que en Sannazaro.

También es probable la intención metaliteraria del debate entre los pastores, cuyos nombres quizás solo son las máscaras de los poetas Virgilio (Títiro), Sannazaro (Sincero) y Luca Valenziano (Licano). En este caso, se daría en este Atto pastorale una configuración semejante a la de la égloga Ursus de Anisio, ya que ambos reconocen y representan dentro de su obra la genealogía del mismo género, regido por Virgilio y su émulo Sannazaro, del mismo modo que él mismo lo había escenificado en su égloga Galatea. Resulta interesante, además, observar que tanto en el caso de Valenziano como en el de Anisio, justo después de Sannazaro, se da una lectura cortesana del mito de Galatea,

73. Ibid., fol. $\mathrm{K}$ iii $\mathrm{v}^{\circ}-\mathrm{K}$ iv $\mathrm{r}^{\circ}$. 
y más concretamente relacionada con el casamiento de un noble con una dama. Se puede afirmar, en resumidas cuentas, que la imitación de Virgilio y de Sannazaro adquiere, en los años 1520-30, el carácter de un programa que los poetas pueden poner al servicio de un discurso sobre el lugar del amor en la corte, como demostración de lo que hay que evitar (el amor ferino, elegíaco, identificable con Polifemo) y de lo que hay que buscar (el amor honesto, que es amor de la virtud y de las ideas). No se trataría en realidad de otra cosa sino del empleo, por parte de un discurso cortesano y neoplatónico, de lo que sugería Pontano en su Antonius.

Un último ejemplo, ya posterior a las églogas de Garcilaso $^{74}$, es el de las «canzoni pescatorie» que su amigo Luigi Tansillo compondría para don García de Toledo. El inicio de la queja del pescador Albano recuerda en efecto claramente el exordio de la queja de Salicio ( $i \mathrm{O}$ más dura que mármol a mis quejas...»): "O Galatea, al pianto mio più salda / che scoglio, piú fugace / che vento e piú crudel che tutto'l mare..." ${ }^{75}$.

En el cancionero manuscrito que formaría en 1555 para Ruy Gómez de Silva, Tansillo declara la función de estas canciones piscatorias:

Se per ventura il signor don Garzía di Toledo fusse ora costí [...], faccia Vostra Signoria ch'egli le sia l'interprete di queste mie canzoni pescatorie, le quali io composi a tempo che con lui io navigava. E furono veramente parturite nell'istesso luogo dove ora Albano pescatore sintroduce cantarle, cioè a piè del monte di Lipari. Nacquero anch'elle tutte tre d'un parto, si come quelle di Cintia; chi fusse il pescator et gli altri misteri dentro lor nascosti, tanto vie piú chiaramente potrà egli dichiarare, quanto piú agevolmente ciascun uomo può sapere piú che le strane le sue proprie cose, salvando alcuni che, per cercar di saper le altrui, ignoran le loro. ${ }^{76}$

El testimonio resulta interesante por lo que revela de las condiciones de su escritura -la situación amorosa de un don García de Toledo abandonado por su amada, doña Antonia de Cardona-, pero también, y ante todo, por el carácter necesariamente secreto de las identidades que se esconden bajo los nombres de los pastores y de las ninfas. Lo mismo se deduce de lo que Girolamo Ruscelli escribiría a propósito de un Capitolo en terza rima compuesto por el mismo Tansillo para don García:

Il qual cavaliero, non è alcuno dubbio, che non meno, oforse ancor molto di più, che per valersene in arme, fu condotto da quel Signore con esso per lui per suo Orfeo, a tenerli

74. Algunos comentaristas, desde F. de Herrera (Anotaciones..., op. cit., p. 702), lo adujeron como fuente posible para Garcilaso, pero el hecho de que, como se recuerda aquí a continuación, haya sido compuesto para don García de Toledo (nacido en 1514), hace poco probable que sea anterior al poema del toledano. Sus últimos editores, Tobia R. Toscano, Erika Milburn y Rossano Pestarino (Luigi Tansillo, Rime, Roma, Bulzoni Editore, 2011, t. I, p. 346), restringen las fechas de composición entre 1538 y 1543, considerando como posible la propuesta de 1540 hecha por Pèrcopo (Luigi Tansillo, Il canzoniere edito ed inedito secondo una copia dell'autografo ed altri manoscritti e stampe, ed. Erasmo Pèrcopo, Napoli, Società Editrice della Biblioteca di scrittori meridionali, 1926, vol. I, p. 204).

75. Luigi Tansillo, Rime, op. cit., pp. 342-343.

76. Ibid., p. 519. 
di continuo con la leggiadria delle rime sue, sereno e felice l'animo in tal'amore, e fra molte bellissime stanze, canzoni e sonetti, che se ne son veduti, fu quel Capitolo in terza rima, che è in istampa, il quale il detto Luigi fece nel partir loro a nome di esso Don Garuia, parlando un astratto alla vera Donna da lui amata. Ma per rispetto della secretezza, che di sopra ho detta, il Capitolo fu publicato e sparso per Napoli, come fatto, o composto dal detti Luigi, non per Don Garzia, ma per se medesimo. ${ }^{77}$

El poeta sirve al mecenas prestándole su voz de Orfeo, para plasmar aquello que el príncipe quizás no sepa expresar con igual sutileza y que, en todo caso, no debe, por conveniencia, decir de modo público. Se percibe, así, un papel del poeta como portavoz de su señor que corresponde a la perfección con las declaraciones de intención iniciales, las propositiones, con que Tansillo y los demás poetas de su generación adornan la apertura de sus poemas.

Sabiendo el estrecho vínculo de estima, pero también de apoyo, que unió Tansillo a Garcilaso, que ostentó como él la función de contino y que, incluso, le abrió la corte del padre de don García, don Pedro Álvarez de Toledo, parece necesario considerar que existiera la misma relación entre Garcilaso y su protector, o sus protectores, los miembros de la casa ducal de Alba -del "estado albano" que tanto Garcilaso como Tansillo celebraran en sus versos-. El contexto a la vez estético y político de la Nápoles virreinal desempeńó, pues, un papel decisivo para la composición de la égloga, y en especial para la ideación de la imagen de Galatea. La égloga garcilasiana se ha de comparar con creaciones semejantes de amigos y compañeros del toledano en Nápoles, en las que aparecen otras tantas galateas esquivas, huidizas y, al mismo tiempo, adoradas como ejemplos perfectos de un ideal de belleza femenina que quedaría asociado a la estética de Garcilaso ${ }^{78}$.

A las aquí recordadas, habría que añadir otras, contemporáneas o ligeramente posteriores. Este es el caso de la égloga Galatea de Bernardo Tasso, publicada en sus Rime (1534), o de la égloga Galatea, over Magia, de Berardino Rota, editada por Scipione Ammirato en los Sonetti et canzoni, con l'egloghe pescatorie (1560),

77. Le imprese Illustri con espositioni, et discorsi del Sr. Ieronimo Ruscelli, Venezia, Francesco Rampazetto, 1566, fol. $265 v^{\circ}$. Véase Erika Milburn, Luigi Tansillo and Lyric Poetry in Sixteenthcentury Naples, Leeds, Maney Publishing, 2003, p. 57.

78. El Polifemo fue sometido al dictamen de Pietro Bembo, quien le mandó en 1546 una larga carta a B. Martirano con observaciones de índole ante todo lingüística. El texto del poema no se publicó, sin embargo, hasta 1874, en Francesco Fiorentino, Bernardino Telesio ossia studi storici su l'idea della natura nel Risorgimento italiano, Firenze, Successori Le Monnier, 1872-1874, vol. II, pp. 426-465. Hay edición más reciente: B. Martirano, Aretusa. Polifemo, ed. Pasquino Crupi, Soveria Mannelli, Rubbettino, 2002. Véase Giovanna Mereu, «Polifemo e Galatea: riscritture del mito da Teocrito a Bernardino Martirano", Aufidus, no 62/63, 2007, pp. 55-85. El Cyclops de Coriolano, en cambio, sí que ya se publicó en el siglo XVI: Coriolani Martirani Cosentini Episcopi Sancti Marci. Tragcedic. VIII. [...] Comoedia II. [...], Neapoli, Giovanni Maria Simonetta, 1556. Para los vínculos de los hermanos Martirano con el ámbito napolitano, véase la introducción de Tobia R. Toscano a Bernardino Martirano, Il Pianto d'Aretusa, Napoli, Loffredo Editore, 1993, pp. 7-49, reed. en id., Letterati, corti, accademie. La letteratura a Napoli nella prima metà del Cinquecento, Napoli, Loffredo Editore, 2000, pp. 265-298. 
pero de redacción contemporánea a la época de Garcilaso ${ }^{79}$. Otros textos se habrían de citar aún, como el Polifemo, en toscano, de Bernardino Martirano, de la década de 1540, o el Cyclops, en latín, de su hermano Coriolano.

El papel de modelo de Nápoles es, pues, doble: por un lado, por las múltiples influencias de los poetas neolatinos, cuya huella se concentra en la ciudad partenopea; por otro lado, por la dimensión cortesana de las églogas de Garcilaso, comparable con lo que se observa en los conjuntos de églogas de sus amigos Bernardo Tasso y Bernardino Rota, concebidas en el mundo de las cortes napolitanas, entre la de los Sanseverino y la de Vittoria Colonna ${ }^{80}$.

El que no se pueda determinar la intención cortesana de la égloga I de Garcilaso por la obligada secretezza -es decir, por la falta de documentos-, más allá de la propositio del mismo poema, no significa que no la haya habido. El uso del mismo nombre de Galatea sugiere que se trate de un discurso sobre el amor, como fuera el caso de Sannazaro, de Anisio o de Valenziano, como los versos iniciales del idilio XI de Teócrito ya lo sugerían y como lo confirma el uso del mito de Galatea por "Antonius» en el diálogo de mismo nombre de Pontano. Cabe pensar que el contexto de la composición de la égloga I haya sido pre-matrimonial -recuérdese que don García, nacido en 1514, tendría entonces ya unos veinte años-. No parece de recibo, en todo caso, la idea según la cual los cantos de Salicio y de Nemoroso representarían simplemente las desdichas amorosas del propio Garcilaso, o de Garcilaso con su amigo Boscán, como se viene afirmando desde el siglo $\mathrm{XVI}^{81}$.

De aquellas circunstancias particulares, ahora desdibujadas por el olvido, solo queda lo que Garcilaso, llevado por el ejemplo de Teócrito, de Virgilio y de Petrarca, plasmó en torno al nombre de Galatea, la idea de la belleza a la par admirable y temible. La canonización de una obra de arte suele elevarla a las esferas de la pura estética, lo cual oblitera la significación y las circunstancias históricas de su creación. Este es el caso de la poesía de Garcilaso de la Vega, considerada desde el siglo de su creación como un parangón de perfección estética, a costa de un olvido de sus evidentes implicaciones cortesanas y políticas. Los comentarios que El Brocense y Herrera hicieran de su obra lírica insistieron únicamente en sus cualidades estéticas. La poesía lírica se diferencia en esto de la épica, que suele expresar con más claridad el proyecto encomiástico y los presupuestos históricos que la definen, mientras que el texto lírico solo

79. Véanse Bernardo Tasso, Rime, ed. Domenico Chiodo, Torino, Edizioni RES, 1995, pp. 272-275 y Bernardino Rota, Egloghe pescatorie, ed., introd. y notas Stefano Bianchi, Roma, Carocci, 2005, pp. 95-100.

80. Sobre lo cual, véanse las demás contribuciones a este número del Bulletin hispanique, y en especial la de Gáldrick de la Torre, «El grupo poético de Ischia y la adaptación al vulgar de la égloga piscatoria», así como el libro sugestivo de Raffaele Girardi, Finzioni marine. Travestimento e mito nella civiltà di corte, Roma, Bulzoni Editore, 2009.

81. Una útil revisión de esta cuestión para la égloga III ha sido propuesta por Eugenia Fosalba, «Implicaciones teóricas del alegorismo autobiográfico en la égloga III de Garcilaso», Studia Aurea. Revista de Literatura Española y Teoría Literaria del Renacimiento y Siglo de Oro, vol. 3, 2009, pp. 39-104, http://www.studiaaurea.com/articulo.php?id=98. 
merece ser recordado por su índole estética, no por su significación política, que resulta caduca algunos años después de su composición. La Galatea de Garcilaso es la que dejaría la huella más profunda en la memoria literaria de la lengua castellana, y es más que probable que tanto Cervantes ${ }^{82}$ como Góngora $^{83}$ la tuvieran presente a la hora de concebir sus obras homónimas. Esto no fue posible, sin embargo, sin un proceso de ahistorización que radicaba en el papel de arquetipo estético que habían ido cobrando las creaciones garcilasianas, y que ya resulta evidente en los comentarios de Francisco de Las Brozas, en 1574, y de Fernando de Herrera, en 1580.

82. Sobre la relación de La Galatea de Cervantes con Garcilaso, véase Edward Dudley, "Goddess on the Edge: The Galatea Agenda in Raphael, Garcilaso and Cervantes», Caliope, vol. 1, no 1-2, 1995, pp. 27-45, en el que dibuja un paralelismo entre la novela pastoril de Cervantes y la Galatea de Rafael por un lado, como cumbres de arte manierista, y entre la égloga I de Garcilaso y el arte quattrocentesco de los bustos femeninos de Francesco Laurana. La perspectiva así creada, que no compartimos, ha sido revisada por el propio Dudley, en el artículo ya mencionado (“ $\mathrm{i} \mathrm{O}$ más dura que mármol a mis quexas!”...»), donde hace de Garcilaso el introductor del manierismo en España: «[...] we can see now that what Garcilaso provided was not just a rejection of the Italian master, but the crucial step beyond Petrarch. He was entering a new poetic terrain that we have come to call Mannerism». Al margen del uso opinable de la categoría de «manierismo», parece, en efecto, más probable, según se ha procurado mostrar aquí, ver en Garcilaso el heredero del movimiento artístico e intelectual que brota en la Roma y en la Nápoles de inicios del Cinquecento.

83. Para la lectura gongorina del mito y sus fuentes, véase L. de Góngora, Fábula de Polifemo y Galatea..., op. cit. Cabe subrayar, además, que Góngora se sitúa plenamente en la estela de la tradición aquí reconstruida con los vv. 512-611 de la Soledad segunda, en el "piscatorio cántico» de Lícidas y Micón -cuyos nombres recuerdan aquellos de los pescadores de la primera égloga piscatoria de Sannazaro-; sobre lo cual, véase en especial a Mercedes Blanco, Góngora heroico. Las «Soledades» y la tradición épica, Madrid, CEEH, 2012, pp. 151-169. 
